\title{
The Effect of Purchasing Welfare on Consumer Purchasing Behavior: the Role of Mediator Attitudes
}

\author{
${ }^{1}$ Aida Azadi, ${ }^{1}$ Ali Zarei*, ${ }^{1}$ Farshad Tojari \\ ${ }^{1}$ Faculty of Physical Education and Sport Sciences, Islamic Azad University, Central Tehran Branch, \\ Tehran, Iran.
}

Submitted 04 September 2018; Accepted in final form 01 December 2018.

\begin{abstract}
Background. Despite the research being accomplished so far, there is no clear answer to the question whether purchasing welfare is affected by the attitude of customer purchasing behavior. Objectives. The aim of this study was to investigate the effect of purchasing welfare on consumer purchasing behavior and to assess the mediator role of attitudes in this regard. Methods. This was a descriptive-correlational study conducted using a survey method. The statistical population of the study consisted of all young consumers of sporting goods (15-30 years old) in Isfahan city. In this study, there were 23 free parameters in the proposed model. The sample size was considered for each free parameter of 15 people. Finally, 350 people were estimated. Purchasing welfare (Edley et al., 2013), attitudes (Lee and Trill, 2012) and consumer purchasing behavior (Edwards, 1998) were used as the instruments and their face and content validity and reliability were confirmed $(0.75,0.80,0.81)$. Data were analyzed using Amos-22 software. Results. The research model had a favorable fit. Also, the mediator attitude was a partial relationship between purchasing welfare and purchase behavior $(\mathrm{P}<0.05)$. Conclusion. Consumer welfare increased the behavior of consumer purchasing, but with the increasing consumer attitude in the relationship, the impact of purchasing prosperity on behavior increased.
\end{abstract}

\section{KEY WORDS: Consumer Life, Social Welfare, Local Life, Positive Attitudes, Models, Structural}

\section{INTRODUCTION}

Sport consumer behavior research represents a sub-discipline within the academic field of sport management and its evolution follows a similar trajectory as the general field of consumer behavior. Consumer behavior emerged as a subdiscipline of marketing in the early drawing upon a variety of other disciplines, including psychology, sociology, anthropology, economics and general education to investigate an individual decision-making process (1). Sport consumer behavior research draws upon this multidisciplinary approach with notable influences from social psychology and marketing with one important distinction; the assumption that sport has unique characteristics (2). Sport scholars and educators highlight intrinsic characteristics of sport products (The term sport product includes goods and services) related to the uncertainty of outcomes, fluctuations in supply and demand, sport's intangibility and inconsistent nature, reliance on product extensions, the possession of more knowledge by sport consumers and the manner in which sport is consumed in the presence of others (3). Although the uniqueness of these characteristics can be debated and the assumption questioned empirically (4), the observed emotions and connections created from watching or participating in sport is evident, and the study of sport consumer behavior remains a popular topic in sport management journals (5-7).

*. Corresponding Author:

Ali Zarei, Associate Professor

E-mail: dr_alizarei@yahoo.com 
Sport consumer behavior researchers should consider the unique characteristics of sport to provide sport organizations with actionable recommendations. Developing and delivering sport experiences to meet the needs and wants of sport consumers has implications for sport organizations, whose purpose is to provide sport consumers with a pleasurable experience by focusing on service quality and satisfaction to achieve organizational goals. However, sport consumption is largely subjective in nature and involves experiences based on interactions between individual consumers and the sport environment which consists of physical and technology mediated experiences $(8,9)$. Consequently, sport consumer behavior academic research has to account for a vast array of psychological and physiological needs and responses that occur before, during and after the use or anticipated use of a sport experience (10). In addition, academic promotion requirements, refereed journal publishing cycles and data access prompt researchers to strategically target their research on a specific aspect or temporal period which often dictates the methodology used. To help academic researchers with this strategy and publishing in SMR, a panel of academic scholars was consulted to gain insight into their perceptions of sport consumer behavior. The next section presents insight gained from these scholars.

Behavior and psychological conditions during purchase have been under focus by researchers in the recent decades. Varieties of consumer behaviors are due to a variety of influencing factors on individual behavior and motivation of the buyer which part of it is influenced by market or market space, marketing, advertising, brand and brandism and partly influenced by the customers' internal factors including thoughts and feeling of buying selective items (11). The existence of different consumer groups indicates wide variation for the market of a product, therefore, consumer perception behavior is very important (12). There are various factors in consumer behavior that shape consumer attitudes and behaviors. These factors can be categorized to negative and positive groups. The negative factor group, such as guilt $(13,14)$ means as repentant feeling of regret shopping. But there is welfare of purchase in the positive factor group that plays an important role in this field. Today, research on welfare is growing. Welfare is defined as positive assessment of life and balance among positive and negative affections. The concept of shopping welfare has recently paid attention to marketing literature and shopping centers and retailers. Purchasing welfare is purchasing buyers' perception of shopping centers that is helped to satisfy important areas of life (such as consumer life, social life, welfare and local life) and leads to a global judgment that the shopping center significantly contributes to the overall quality of individual life (15). The concept of the welfare of purchases does not represent satisfaction of purchase or satisfaction of different parts of shopping center (e.g. parking satisfaction, stores, products and services), but the level of purchase experience in a shopping center influence person life quality perception which describes this concept. In other words, welfare purchasing concludes the sates of life satisfaction that consumers experiences through their own experiences at a shopping center. Therefore, the concept of welfare is fully different from concept of the related creation (affection), such as the pleasure of buying and other scale of affection associated with the purchase center (16). These structures are merely a sense of instant satisfaction, the talent and static purchasers who experience purchases while ignoring the dynamic and long-term purchasing affect overall sense of individual welfare. Hence, the welfare purchasing can have an impact on consumer purchasing behavior. (Lee, 2014) stated that information is rightly received by consumers, shaping their attitudes and influencing their purchasing behavior (17).

According to the Theory of Reasoned Action (TRA), the best prediction of behavior is the person intention to engage in behavior. The intention is predicted by two variables of behavioral attitude (positive or negative total assessment of behavior) and abstract norms (general understanding of social pressure for behavior or non-behavior) (18). Also, based on Dick and Basu's loyalty theory, customer loyalty is a combination of desirable attitude and repetition of purchase or sponsorship. Therefore, when a customer experiences a welfare shopping, he or she would find positive attitude toward the product and his or her loyalty and loyalty would be determined by the repetition of purchasing the product. Literature of organizational behavior shows that employees with the higher well-being psychology, have more commitment to 
organization and have less willing to leave their jobs (19).

Similarity, Sergie, Lee and Chrisman (2006) have shown that consumer psychological wellbeing is associated with their positive attitude and loyalty to product, in consumer and marketing literature. The behavior-related attitude is defined as being susceptible to responding favorably or undesirable to an object. In other words, if a person believes that conducting a behavior leads to desirable results, he or she would have positive attitude toward it. But if he or she believes that it leads to an undesirable behavior, he or she would have a negative attitude (20). According to this theory, more desirable attitude tends to predict more intense behavioral intent (21). Consumer studies about purchasing products have shown that consumer behavioral intent is shown by two components of attitude and subjective norms (22). Based on the above theory, when one gets positive results from buying a product and increasing the welfare purchasing, buyer attitude toward the product is more positive and predicts him or her purchase behavior. Also obtaining the negative results of products can be caused to make consumers attitude negative and decrease the likelihood of buying. Therefore, it has the mediator role in the context of the purchase prosperity and future behavior.

Consumers have been one of the most important issues for marketing researchers in the recent decades. The variety of consumer behavior is due to a variety of factors affecting individual behavior and individual incentive to purchase. Existence of different consumer factors for the markets of a product indicates a wide variation. Today, consumer is considered as the main key to success or failure of a company. Thus, studying and discovering the needs of consumers and analyzing the process of consumer behavior and prioritizing the factors influencing this process are among the major tasks of marketers, thus identifying the target market tastes and offering the good product or service to that market. But consumer behavior has a high complexity, so that at the moment of purchase, the syntax of buying, the choice of product has many variables including the amount of interest and interest in the product, the individual ability to economize and the quality and performance of the product. However, few studies have taken into account the role of positive factors in the formation of buying behavior such as psychological well-being. In Iran, there are not any positive factors in shaping consumer attitudes such as consumer welfare in resource users and research activities. These concepts, which have created a huge transformation in marketing science and consumer value, are still to be left. Therefore, research activities in this field certainly create a new insight and attitude in the field of consumer ethical values and provide the necessary ground for conducting consumer purchasing behavior. This issue is so important in this regard, which can be helped to the business, industry owners and marketers to pay attention and assess the consumers' attitudes to increase sales of products. Therefore, this research seeks to answer the question whether purchasing welfare influences behavior of consumers and if consumers' attitude plays as a mediator in this relationship.

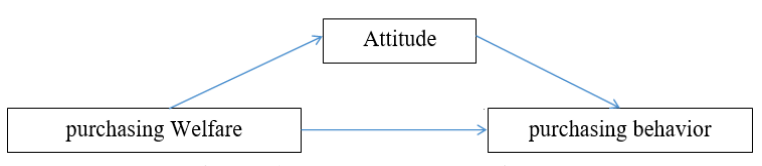

Figure 1. Proposed theoretical model

\section{MATERIALS AND METHODS}

Method. This was a descriptive-correlational study conducted using a survey method.

Participants. The population included all youths of sport goods consumers (15-30 years old) in Isfahan. In this study, there were 23 free parameters in the proposed model. The sample size was considered for each free parameter of 15 people. Finally, 350 people were estimated.

Research Tools. The data collection was performed as field method using a questionnaire. The questionnaire used in the research was first translated into Persian from English. Afterward, was returned by an English expert from Persian to English and was edited in cases of nonconformance. Content validity depends on judgment of judges. The researcher after obtaining permission and translation of the questionnaire, consulted 8 professors of sport management and commercial management due to the variability of the research community to remove, modify and destroy it. In this way, the face validity of the questionnaire was examined. Finally, by reviewing the experts' opinions, final adjustments were made to the tools and their content validity was confirmed and guaranteed. To assess consumer's welfare purchasing, Peloza, White, Shang (2013) scale in 4 important areas of life, means consumer life, social life, welfare and local life was used. Reliability of questionnaire 
was 0.757 using Cronbach's alpha. For measuring the consumer's attitude than sport goods purchase Lee \& Trail's (2012) attitude questionnaire was used. The reliability of this questionnaire was 0.809. For measuring the purchase behavior, Edward's questionnaire (1998) was used. The reliability of questionnaire was 0.814 using Cronbach's Alpha. Likert's four-scale from totally disagree to totally agree was considered for each question.

Statistical Analysis: Structural equation modeling using AMOS software was used to examine the model fit and the role of mediation.

\section{RESULTS}

Descriptive statistics of gender indicated that $49 \%$ of the subjects were women and $51 \%$ men. Most of the research samples were in the age range of 18 to 22 years and had a bachelor's degree. Most research cases were single. However, $36 \%$ of subjects had an income below 500,000 Iranian Rials and the lowest was 5.7\% with monthly income of 15 to 20 million Rials. According to the table below, there was a slight difference between posterior, median and mean, and the skew coefficient and peakeness coefficient were less than 0.7, therefore, distribution of data was normal and mean as the indicator of the central tendency indicator was used using parametric statistics models.

The model of purchasing welfare relationship with purchase behavior with mediating attitude is represented in Figure 2. The purchase behavior variable is an exogenous obvious variable of attitude variable, latent variable while latent purchasing welfare variable is considered as latent endogenous variable. The error measuring variables of e1-e8 is structural error of e10-e9 model.

Based on the results in Table 2, Chi-square index was 2.874 , indicating that this pattern has a satisfactory status. The value of the TLI and CFI comparative indices were above 0.9. The PCFI value was also a good fit index of over 0.5 and was desirable. The value of RMSEA as the most important index of general fit was 0.069 showing that in general, the pattern had a fairly good fit.

As shown in Table 3, the coefficients of attitude influence on purchasing behavior (0.46) and purchasing welfare on purchasing behavior (0.28) at the level of 0.01 and the effect of purchasing welfare on attitude (0.16) at level 0.01 was meaningful.

Table 1. Statistical indexes related to the study of variables

\begin{tabular}{|lccccccccc|}
\hline Variable & \multicolumn{3}{c}{ Distribution Indicators } & \multicolumn{2}{c}{ Dispersion Indicators } & \multicolumn{3}{c|}{$\begin{array}{c}\text { Indicators of central } \\
\text { tendency }\end{array}$} \\
& $\begin{array}{l}\text { Peakeness } \\
\text { Coefficient }\end{array}$ & $\begin{array}{c}\text { Skew } \\
\text { Coefficient }\end{array}$ & $\begin{array}{c}\text { Standard } \\
\text { error }\end{array}$ & $\begin{array}{c}\text { standard } \\
\text { deviation }\end{array}$ & variance & $\begin{array}{c}\text { variation } \\
\text { range }\end{array}$ & Mean & Middle & Mode \\
$\begin{array}{l}\text { purchasing } \\
\text { welfare }\end{array}$ & 0.501 & -0.624 & 0.038 & 0.713 & 0.509 & 3.75 & 3.85 & 4 & 4 \\
$\begin{array}{l}\text { consumer } \\
\text { purchasing } \\
\text { behavior }\end{array}$ & -0.157 & -0.492 & 0.054 & 0.853 & 0.728 & 4 & 3.56 & 3.50 & 3.50 \\
attitudes & -0.065 & -0.630 & 0.043 & 0.812 & 0.660 & 4 & 3.93 & 4 \\
\hline
\end{tabular}

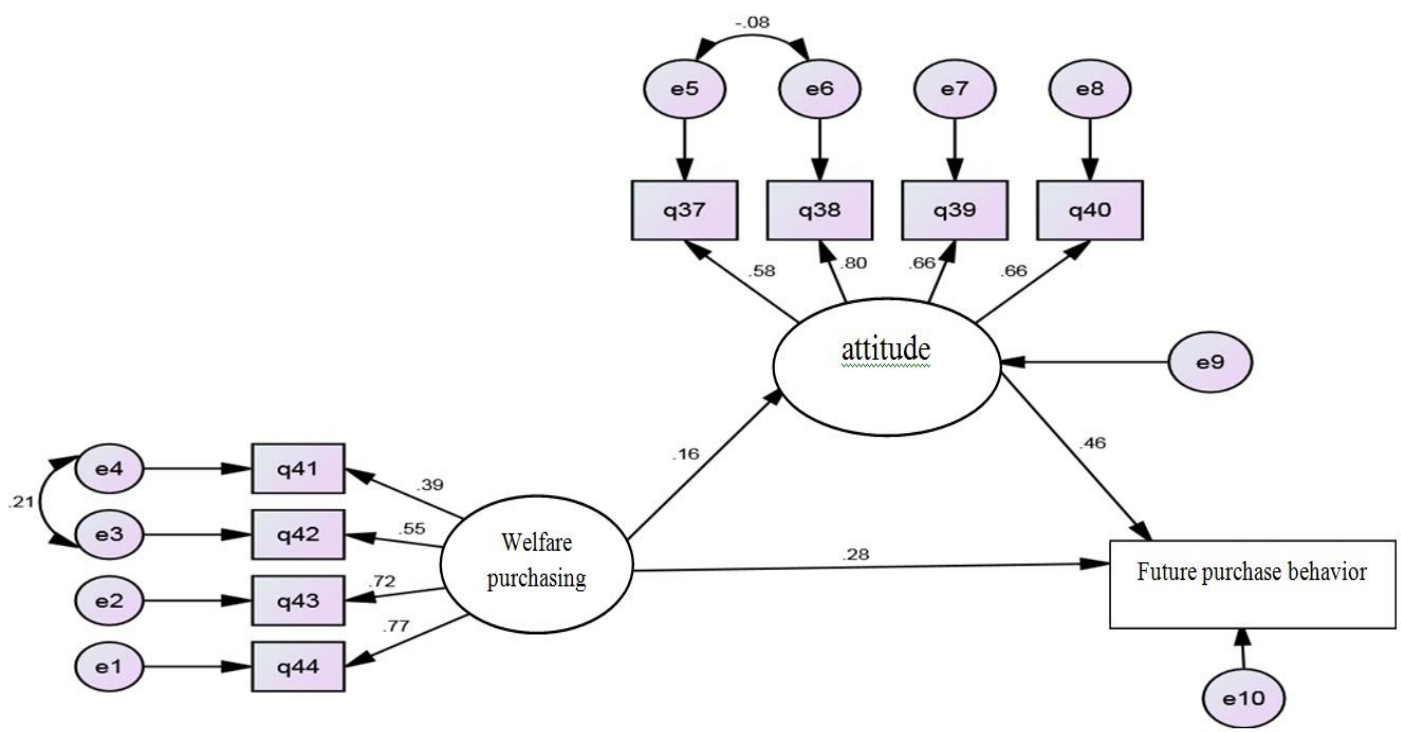

Figure 2. The model of purchasing welfare relationship with purchase behavior with mediating attitude 
Table 2. Multivariate normalization and general indexes of fitness in general pattern

\begin{tabular}{|c|c|c|c|c|c|c|c|}
\hline \multicolumn{8}{|c|}{ Fit Index } \\
\hline \multicolumn{3}{|c|}{ Absolute } & \multicolumn{2}{|c|}{ comparative } & \multicolumn{3}{|c|}{ frugal } \\
\hline CMIN $^{1}$ & $\mathrm{DF}^{2}$ & $\mathbf{P}^{3}$ & TLI $^{4}$ & CFI $^{5}$ & PCFI $^{6}$ & CMIN/DF ${ }^{7}$ & RMSEA $^{8}$ \\
\hline 2206.925 & 768 & 0.001 & 0.908 & 0.936 & 0.585 & 2.874 & 0.069 \\
\hline
\end{tabular}

${ }^{1}$ Chi-Square, ${ }^{2}$ Degree of Freedom, ${ }^{3}$ P value,${ }^{4}$ Tucker-Lewis Index,${ }^{5}$ Comparative Fit Index,${ }^{6}$ Parsimonious Comparative Fit Index, ${ }^{7}$ Normed Chi-Square, ${ }^{8}$ Root Mean Squared Error of Approximation

Table 3. Model path coefficients

\begin{tabular}{|lcccc|}
\hline Parameter & Standard Estimates & significance & Standard Error & Critical ratio \\
purchasing welfare $\rightarrow$ attitudes & 0.158 & 0.016 & 0.045 & 2.404 \\
attitudes $\rightarrow$ purchasing behavior & 0.458 & 0.001 & 0.096 & 7.063 \\
purchasing welfare $\rightarrow$ purchasing behavior & 0.279 & 0.001 & 0.055 & 5.207 \\
\hline
\end{tabular}

Table 4. Estimating the total, direct and indirect effects of research variables

\begin{tabular}{|lcccccc|}
\hline Effects & Standard Estimates & significance & Bottom bounds & Upper bounds & Non-Standard Estimates & significance \\
Total & 0.351 & 0.007 & 0.214 & 0.472 & 0.358 & 0.009 \\
Direct & 0.279 & 0.006 & 0.154 & 0.504 & 0.284 & 0.007 \\
indirect & 0.073 & 0.016 & 0.126 & 0.154 & 0.074 & 0.024 \\
\hline
\end{tabular}

The results in Table 4 show that the effects of purchasing welfare on purchasing behavior, which is the sum of the direct effect of purchasing welfare on purchasing behavior and its indirect effects through attitudes, is estimated at a total value of 0.351 and significant at 0.007 and zero is not between the upper and lower bounds, which indicates the significance of the total effects. The direct effect of purchasing welfare on purchasing behavior is 0.279 and its significance is 0.006 and zero is not between upper and lower bounds which indicates the significance of this effect. As a result, the direct effect of purchase welfare on meaningful purchasing behavior. The indirect effects of purchase on the behavior of purchases, which are the product of the direct effect multiplication, are 0.073 , which means that the significance is not equal to 0.016 and zero between the upper and lower bounds, which indicates the significance of this indirect effect.

In this way, the indirect effect of purchasing welfare on purchasing behavior is significant. Considering that direct effect is significant, it shows that the mediator's attitude is a partial relationship between purchasing welfare and purchasing behavior. In other words, consumer welfare increases and impacts consumer purchasing behavior, but with the increasing consumer attitude in the relationship, the effect of purchasing welfare increases on behavior.

\section{DISCUSSION}

The increasing prevalence of technology and its impact on the sport user experience highlights one of the challenges and opportunities that sport organizations face moving forward. As noted in the panel comments, sport organizations would have to respond to individualization and personalization, generational shifts, commercialization and social and health benefits of sport when designing and delivering sport experiences. Hence, when investigating the sport user experience, a sport organization's unique characteristics should be considered as it reacts to environmental forces and consumer perceptions (23). This management perspective is often neglected in sport consumer research, given that management decisions and activities are often unobserved by sport customers. However, organizational characteristics would influence the production of touch points and interactions that occur within the sport context and can determine whether sport user needs are being met. Therefore, this study examined the effect of shopping welfare on consumer purchasing behavior as the role of mediator attitude. The findings of this research showed that purchasing welfare has positive effects on purchase behavior and by adding the consumer attitude in this relationship, the effects of purchasing welfare would increase on purchase behavior. These results are consistent with the results of Lim et al (2016) and Yadav \& Pathak (2016) who concluded that among the external factors, the name and brand of the goods, the economic status of the customer, the efficiency and attractiveness of the goods have the most effects on behavior of the buyer and among the internal factors of the feeling of compulsion from buying, enjoyment of purchasing, coping reaction to buying tendencies and experience. The positive effect of the previous purchase is the highest $(24,25)$. Accordingly, the present research results stated that the concept of well-being of purchasing is based on the concept of consumer well-being. Consumers' welfare refers to consumer satisfaction regarding various consumer life 
domains and its subsets. That is, the concept of consumer welfare is defined at a macro level among the types of market experiences in the area of consumer purchasing. Hence, in explaining the effect of purchasing welfare on the behavior of purchasing, it can be explained by classical and instrumental learning. When a consumer makes a purchase that leads to satisfaction in different areas of life, this purchase and product acts as a booster for him or her. It may even be anything that connects the product, such as advertising (26, 27). The product or vendors also acts as a secondary booster. In this case, a person repurchases for re-amplifying the product due to that product. Also, based on the classroom learning process, a product that can meet the basic needs is a booster that appears every time this boost appears to be the behavior of the purchase. It is possible that, based on the silent process in this learning, even if the product fails to reach the counterpart, the person would buy the product. But in the long run, the continuity of behavior continues as long as the product can satisfy the needs of the consumer and give him satisfaction.

Other results of research showed that the attitude in the welfare purchasing and future purchase behavior has a mediator role. In explaining this part of model, this question must be answered that how much attitudes lead to behavior. Psychologists believe that the more accessible attitudes, the better act to them. Attitudes are used to interpret selective perceptions of object and meaning of situations. Attitudes can affect cognitive processing. These results are consistent with the results of Badgaiyan and Verma (2015) who concluded that in sports sales, some factors play role such as brand, advertising, seller behavior, along with being overwhelmed and blamed on the future behavior of consumer shopping for sports goods (28). These findings confirm previous literature suggesting identification acts as an antecedent to perceived value $(29,30)$ and has a direct positive association with purchase intentions (31-33). The current results also enhance the previous literature by demonstrating these associations within a payper-view sport setting. Therefore, attitudes are stored in long-term memory and four important functions take up for the consumer. First, a profitable operation indicates that people express their feelings in such a way as to maximize encouragement and at least punishment on the part of others. In this sense, expressing an attitude, such as the conditional response, acts as an actor. For example, a seller maybe understands that positive statements against a customer (means expressing favorable attitudes) would increase the chance of selling (it means a positive amplifier). Second, attitudes can defeat themselves. Attitudes, in the role of self-defense, protect people from primitive truths about themselves or from the violent reality of the outside world. Another example is that smokers form positive attitudes about smoking to defeat themselves against the reality of what they do. Attitudes in third and fourth roles provide knowledge function and exalted values. Attitude roles same as structures facilitate decisions in knowledge function. For example, consumers may have attitudes toward specific retailers or stores. The knowledge function also helps to explain the effects of loyalty to brand. Loyalty consumer (to the brand) and maintaining positive attitudes towards a product can be an easy decide by avoiding the long and continuous process of research for information on alternative brand. At least, consumer can show their values and ideas to others by value-based performance. The example of exalted value can be seen in cases where people wear clothes that are decorated with logos (brand) to make a statement about themselves in this way. According to the profitability and the process of conditional activation, if a person profits form a product, he or she repurchases it. According to the selfdefense function, if product can help the consumer to defeat him or herself, the purchase would be occurred again. Also based on the knowledge function of attitude, consumer remains loyal to the brand and purchase which is based on his or her attitudes and makes the decision easier for him or her.

\section{CONCLUSION}

By and large, welfare is a field that seeks to examine cognitive assessments (general judgment about purchasing satisfaction) and emotional (the experience of pleasant and unpleasant emotions) of people buying. The sense of satisfaction and satisfaction with shopping is a component of the positive attitude of people to buying. The concept of well-being is the purchase of a multi-dimensional structure of attitude. In this model, purchasing welfare is designed in a broad way to determine whether a person is aware of his potential, goals, needs, as well as awareness of the product he or she wants to buy. Hence, the purchasing welfare, in 
addition to having a direct impact on purchasing behavior, has also affected consumer attitudes.

\section{APPLICABLE REMARKS}

- It is suggested to marketers to evaluate the satisfaction of their products in regular periods through field surveys among the consumer, and to note that as long as consumer satisfaction is high, his purchasing behavior increases from that product.

- Marketers and manufacturers should note that changing consumer attitudes is a gradual process that can gradually increase consumer purchasing.

- Consumers are advised to make a general program that is tailored to their needs before purchasing.

\section{REFERENCES}

1. Schiffman L, Kanuk L. Consumer behavior. Englewood Cliffs, NJ: Prentice Hall; 2010.

2. Funk D. Consumer behavior for sport \& events: Marketing action. Oxford, UK: ButterworthHeinemann/Elsevier; 2008.

3. Shilbury D, Westerbeek H, Quick S, Funk Karg D. Strategic sport marketing. Crow Nest, NSW Australia: Allen \& Un win Academic; 2014.

4. Baker BJ, McDonald H, Funk DC. The uniqueness of sport: Testing against marketing's empirical laws. Sport Manag Rev. 2016;19(4):378-390. doi: 10.1016/j.smr.2016.02.002

5. Ciomaga B. Sport management: a bibliometric study on central themes and trends. Eur Sport Manag Q. 2013;13(5):557-578. doi: 10.1080/16184742.2013.838283

6. Chelladurai P. Introduction to the Second Inaugural Issue of the Journal of Global Sport Management. J Global Sport Manag. 2016;1(3-4):67-69. doi: 10.1080/24704067.2016.1245514

7. Shilbury D. A bibliometric analysis of four sport management journals. Sport Manag Rev. 2011;14(4):434-452. doi: 10.1016/j.smr.2010.11.005

8. Funk DC, Beaton A, Alexandris K. Sport consumer motivation: Autonomy and control orientations that regulate fan behaviours. Sport Manag Rev. 2012;15(3):355-367. doi: 10.1016/j.smr.2011.11.001

9. Yoshida M, James JD, Cronin JJ. Sport event innovativeness: Conceptualization, measurement, and its impact on consumer behavior. Sport Manag Rev. 2013;16(1):68-84. doi: 10.1016/j.smr.2012.03.003

10.Funk D. Sport consumer behavior: Marketing strategies. Abingdon, Oxon,UK: UK:Routledge; 2016.

11.Pappas N. Marketing strategies, perceived risks, and consumer trust in online buying behaviour. $J$ Retail Consum Serv. 2016;29:92-103. doi: 10.1016/j.jretconser.2015.11.007

12. Blackwell R, DSouza C, Taghian M, Miniard P, Engel J. Consumer behaviour: an Asia Pacific approach: Thomson; 2006.

13.ÖZhan DedeoĞLu A, KazanÇOĞLu İ. Consumer Guilt: A Model of Its Antecedents and Consequences. Ege Acad Rev. 2012;12(1):9-9. doi: 10.21121/eab.2012119542

14.Peloza J, White K, Shang J. Good and Guilt-Free: The Role of Self-Accountability in Influencing Preferences for Products with Ethical Attributes. $J$ Market. 2013;77(1):104-119. doi: 10.1509/jm.11.0454

15.El Hedhli K, Chebat J-C, Sirgy MJ. Shopping well-being at the mall: Construct, antecedents, and consequences. J Busin Res. 2013;66(7):856-863. doi: 10.1016/j.jbusres.2011.06.011

16. Babin BJ, Darden WR, Griffin M. Work and/or Fun: Measuring Hedonic and Utilitarian Shopping Value. J Consum Res. 1994;20(4):644. doi: 10.1086/209376

17.Lee $M$. The effects of product information on consumer attitudes and purchase intentions of fashion products made of fur, leather, and wool. Ames, Iowa: Iowa State University; 2014.

18. Montano D, Kasprzyk D. Theory of reasoned action, theory of planned behavior, and the integrated behavioral model. San Francisco: Jossey-Bass; 2008.

19. Spector P. Job satisfaction: application, assessment, cause, and consequences. Thousand Oaks, CA: SAGE; 1997.

20. Sirgy MJ, Lee D-J, Kressmann F. A Need-Based Measure of Consumer Well Being (CWB) in Relation to Personal Transportation: Nomological Validation. Soc Indicat Res. 2006;79(2):337-367. doi: 10.1007/s11205-005-4920-1 
21.Ajzen I, Fishbein M. Understanding attitudes and predicting behavior. Prentice Hall: New Jersey; 1980.

22. Kim H, Karpova E. Consumer Attitudes Toward Fashion Counterfeits: Application of the Theory of Planned Behavior. Clothing Textiles Res J. 2009;28(2):79-94. doi: 10.1177/0887302x09332513

23.Lock D, Filo K, Kunkel T, Skinner JL. The Development of a Framework to Capture Perceptions of Sport Organizations Legitimacy. J Sport Manag. 2015;29(4):362-379. doi: 10.1123/jsm.2014-0005

24.Lim CH, Kim K, Cheong Y. Factors affecting sportswear buying behavior: A comparative analysis of luxury sportswear. J Busin Res. 2016;69(12):5793-5800. doi: 10.1016/j.jbusres.2016.04.176

25. Yadav R, Pathak GS. Young consumers' intention towards buying green products in a developing nation: Extending the theory of planned behavior. J Clean Prod. 2016;135:732-739. doi: 10.1016/j.jclepro.2016.06.120

26.Park S, Kim Y. The effect of curiosity on the sport media consumption behaviours. Kor J Psychol Ind Organ. 2008;21:493-521.

27.Park S, Kim Y, Park S, In S. The moderating effect of the levels of sport media consumption on consumers' new consumptive behaviors: The epistemic process of sport spectating. Kor J Consum Advert Psychol. 2009;10:437-459.

28. Badgaiyan AJ, Verma A. Does urge to buy impulsively differ from impulsive buying behaviour? Assessing the impact of situational factors. J Retail Consum Serv. 2015;22:145-157. doi: 10.1016/j.jretconser.2014.10.002

29. Kwon Y, Kwak DH. Revisiting the team identification-value-purchase relationship in the teamlicensed merchandise consumption context: A multidimensional consumer value approach. Sport Market Q. 2014;23(2):100.

30. Kwon HH, Trail G, James JD. The Mediating Role of Perceived Value: Team Identification and Purchase Intention of Team-Licensed Apparel. J Sport Manag. 2007;21(4):540-554. doi: 10.1123/jsm.21.4.540

31.James J, Trail G. The relevance of team identification to sport consumption behavior intentions. Int J Sport Manag. 2008;9(4):427-440.

32. Shapiro SL, Ridinger LL, Trail GT. An Analysis of Multiple Spectator Consumption Behaviors, Identification, and Future Behavioral Intentions Within the Context of a New College Football Program. JvSport Manag. 2013;27(2):130-145. doi: 10.1123/jsm.27.2.130

33. Trail GT, Anderson DF, Fink JS. Consumer satisfaction and identity theory: A model of sport spectator conative loyalty. Sport Market Q. 2005;14(2). 